\title{
Franceses ou francófonos? Comparação das trajetórias de dois literatos helvécios: Ramuz e Cendrars
}

Jérôme Meizoz

Haveria trajetórias literárias comuns aos escritores suíços de língua francesa? ${ }^{1} \mathrm{E}$, de modo mais amplo, aos autores de todas as nacionalidades que escrevem em francês, e cujas obras miram o cenário literário da França? Na tentativa de responder a essa questão que não cala no âmbito dos estudos francófonos, torna-se pertinente comparar os percursos de dois autores de uma mesma geração: Charles-Ferdinand Ramuz (1878-1947) e Blaise Cendrars (1887-1961). Suíços de nascença, suas obras circularam de maneira distinta no cenário literário francófono, ao sabor de suas ligações com determinadas instituições.

A evocação de suas trajetórias e do espaço dos possíveis aberto a cada um deles se apoiará em cinco parâmetros decisivos de inserção desses autores - as atitudes domiciliares, editoriais, relacionais, genéricas (gêneros literários praticados) e, por fim, lingüísticas -, com o objetivo de aproximar os diversos processos de consagração que ocorrem nas chamadas "periferias".

\section{Blaise Cendrars}

Filho de pais oriundos de famílias com ascendência alemã (Sauser e Dorner), Frédéric-Louis Sauser, chamado de Freddy, nasceu em 1887 em La Chaux-de-Fonds. Adotou, em abril de 1912, o pseudônimo de Blaise Cendrars, à época de Pâques à New York. Seu pai era um negociante imprevisível que passava por constantes complicações financeiras ${ }^{2}$. Criou-se em

\footnotetext{
${ }^{1}$ Estendi-me mais na análise das situações de Ramuz e de Cendrars em minha tese L'Âge du roman parlant 1919-1939. Ecrivains, linguistes, critiques et pédagogues en débat. Préface de Pierre Bourdieu. Genebra: Librairie Droz, 2001.

${ }^{2}$ Esses dados remetem a Cendrars, Blaise. Blaise Cendrars vous parle. (Paris: Denoël, 1952); Cendrars, Miriam. Blaise Cendrars. (Paris: Balland, 1984); Boillat, Gabriel. A l'origine, Cendrars. (Les Ponts de Martel: Hugues Richard Editeur, 1985); e Touret, Michele. Blaise Cendrars romancier. (Paris: Champion, 1999).
} 
(Cendrars, Blaise. Carta a Hélène, de 11 de abril de 1907, citado por Cendrars, Miriam. Blaise Cendrars Paris: Balland, 1984: 117.)

" (Cendrars, Blaise. Volàvoile, prochronie. Lausanne: Libraire Payot \& Cie., 1931 ou L'Age d'Homme, 1987:64.) "citado por Jaton, Anne. Marie. Histoire littéraire de la Suisse romande, vol. 3. Lau. sanne: Librairie Payot \& Cie. 1996: 491.)

"Cendrars, Blaise. Volà voile, prochronie seguido por Une nuit dans la forêt (1929). Ob. cit.: 1987: 42.) um meio poliglota, acompanhando os pais em reiterados deslocamentos comercias: nascido na Suíça francófona, ele viveu, a partir de 1894, por dois anos em Nápoles, e por três em Bale, onde teve aulas em alemão. Em 1902, retornou a Neuchâtel e entrou para a Escola do Comércio. Adolescente instável, interrompeu os estudos e se empregou na joalheria suíça Leuba, em São Petersburgo. Redigiu suas primeiras "notas de viagem"* após retornar à Suíça por causa de sua namorada Hélène. Sauser logo transforma essas múltiplas errâncias da infância, inicialmente impostas e mal suportadas por ele, em modo de vida, obedecendo à sua "necessidade de evasão" através da viagem*. No verão de 1908, Sauser começou a estudar medicina na Universidade de Berna, mas mudou de opinião e se inscreveu em Letras. Após interromper os estudos, instalou-se em Paris e começou a escrever. Desde 1910, quando ainda era um total desconhecido, ligouse a artistas de Montmartre e tentou encontrar dois autores que admirava: Apollinaire e Remy de Goncourt. Fracassa. Em 1912, na mais completa miséria, conhece a América, onde escreve seu primeiro poema importante, Les Pâques à New Tork.

Educado em moldes burgueses, autodidata e marcado pelo declínio social de sua família, Cendrars não se identificava com as profissões consideradas úteis, nem com as intelectuais, tendo permanecido por muito tempo um estranho para o mundo das letras. Francófilo, mas naturalizado francês apenas no fim da Guerra, ele se considerava um "gringo de Paris"*. Dotado de cultura germânica, dirigiu, então, uma revista franco-alemã, Les Hommes Nouveaux. Tinha horror à poesia helvécia (“[ [...] meu pai escrevia versos suíços, ou seja, versos inferiores, vulgarmente patrióticos")* , entretanto criou laços no país que rejeitava: com o editor valdense Payot $\mathrm{e}$ com seu diretor de coleção Sven Stelling-Michaud, que publicou Vol à voiles (1932), Ramuz e Cingria. Em sua obra, a Suíça quase sempre retorna como paisagem ou alusão.

Não possuía moradia fixa, e foi como marginal do mundo das letras que publicou seus primeiros poemas. Modernidade urbana, vanguarda cubista, tudo o aproximava de um círculo de poetas francófonos que, após a Guerra, tiveram de se definir como dadaístas ou surrealistas. La prose $d u$ Transsibérien lhe conferiu reconhecimento nesse campo lite- 
rário francês restrito. Ao passo que a vanguarda se identificava com o surrealismo, Cendrars se mantinha afastado, tratando os surrealistas de "filhinhos de papai"*. A guerra, em que perdeu um braço em combate pela França, e uma crise pessoal posterior conduziram-no a redirecionar sua produção para o romance. Com a narrativa épica, Cendrars expandiu o seu público de modo espantoso. ${ }^{*}$ Por necessidade econômica, tentou igualmente o jornalismo (Hollywood, Rhum), e, após a Guerra, o rádio. Em termos literários, o hábito de outsider autodidata, devorador de leituras internacionais, incitou-o a recusar qualquer convenção de gêneros literários: nos poemas em versos livres, introduziu elementos narrativos, temas modernistas ou populares; nos romances, mesclava lirismo e aventura, jogando com as tramas nada legítimas do romance popular (Fantomas, Jules Verne).

Cendrars joga, pois, com várias existências literárias: inicialmente, com seus pequenos editores; após, com o editor dos surrealistas (Au sans pareil, de René Hilsum) e, enfim, na Grasset, com que assina em 1924 - mesmo ano do primeiro romance de C.-F. Ramuz em uma grande editora. Na Grasset, mais tarde Denoël, Cendrars entrou, então, para o circuito dos autores de sucesso que a grande imprensa parisiense reconheceu: dissimulando propositadamente suas origens helvécias, foi definitivamente visto como um autor francês, quiçá internacional. Apresentado desde os anos 1930 como um autor francês cosmopolita nos esquemas e na história da literatura francesa, Cendrars permaneceu, em contrapartida, quase ausente da historiografia literária suíça até a década de 1970, quando passou a ser reivindicado com orgulho ${ }^{3}$. O reconhecimento tardio no campo de origem é, aliás, um traço peculiar (como mostra a recepção suíça de Jean-Jacques Rousseau ou de Rodolphe Töpffer). A trajetória de Cendrars alia, pois, labilidade domiciliar, mudança de nacionalidade e conversão entre gêneros (poesia/prosa) à sua entrada definitiva em uma editora de grandes tiragens (Grasset). Enfim, no tocante à língua, Cendrars não recorreu ao francês regional da Suíça romanda como fonte formal ou sinal de pertença. Por outro lado, envernizou seus textos autobiográ-

\footnotetext{
${ }^{3}$ Destacamos, entretanto, a biografia feita por um amigo suíço, Jean Buhler: Blaise Cendrars. Bienne: Le Panorama, 1960.
}

" (citado por Jaton, Anne Marie. Ob. cit.: 1996: 497.)

" (Cendrars, Blaise. L'Or. Paris: Grasset, 1925.) 
ficos com raros termos da sua infância em Neuchâtel (bonasson, [bonachão] em Vol à voiles), ou germanismos suíços incorporados à língua francesa ("loustic", em La Main coupée, no capítulo "Ce loustic de vieil" [Esse velho engraçadinho]).

Sem jamais se reduzir ao subcampo literário da Suíça francesa, ao contrário de Ramuz, o escritor pôde modificar em vários momentos a sua imagem social, e passar de uma área à outra do campo (1912-1919, poesia modernista; 19241938, narrativas de aventuras, jornalismo e até uma encomenda para um panfleto anti-semita, Le Bonheur de vivreinédito, 1937). A pertença de Cendrars a uma periferia francófona parece não haver desempenhado papel significativo em sua integração literária porque rompeu muito cedo o elo de origem, algo ausente no percurso de Ramuz.

\section{Charles-Ferdinand Ramuz}

Filho de pequenos comerciantes de Lausanne, Ramuz estudou letras clássicas, após o que seu pai o estimulou ao magistério. Em 1901, instalou-se em Paris em razão de sua tese ${ }^{4}$. Provinciano, sem acesso verdadeiro a uma rede homogênea, publicou de modo esparso e ao sabor das possibilidades, ao menos antes de sua entrada para a editora Grasset em 1924. A ausência de relacionamentos em Paris, sua nacionalidade, tudo contribuía para fazer dele um passageiro clandestino das letras francesas. Sua modesta caderneta de endereços e um potencial econômico restrito impediam-no de temporizar: Ramuz tirou seus parcos proventos do jornalismo, de notícias fornecidas à imprensa suíça, de aulas, de conferências. Em 1914, com a chegada da Guerra, voltou a contragosto à Suíça, e para sempre. Nos anos 1920, em que foi editado pela Grasset (La guérison des maladies, 1924), sentiu mais que nunca o peso da desvantagem criada pela vida longe da capital. Para preencher a lacuna de sociabilidade, recorreu ao apadrinhamento de autores renomados: Romain Rolland e Claudel. Entre 1902 e 1914, já devia boa parte de suas oportunidades literárias ao apadrinhamento de um protetor suíço, consagrado na França através do movimento naturalista: Edouard Rod, que então escrevia no Journal des Débats, no

${ }^{4}$ Para a trajetória de Ramuz, remeto ao meu ensaio: Ramuz, un passager clandestin des lettres françaises. Genebra: Zoé, 1997. 
Le Figaro e na Revue des Deux-Mondes. Este lhe apresentou escritores (como Gide), seu futuro editor Perrin, e publicou, em 1907, uma de suas novelas no Le Figaro. Rod providenciou também sua candidatura ao Goncourt de 1907. Mas Ramuz fracassou, ao que parece, em virtude de sua nacionalidade e de uma escrita desconcertante, vista como "suíça" (Jules Renard).

Como no percurso de Cendrars, a guerra marcou uma ruptura no processo de reconhecimento de Ramuz na França. De 1914 a 1923, publicou seus livros mais importantes na Suíça. Ao que tudo indica, a série Cahiers vaudois que dirigiu em Lausanne atingiu um público parisiense restrito, porém decisivo: Aragon, Claudel, Copeau e Rivière, por exemplo, liam Ramuz durante a Guerra. Soupault lhe pediu um texto para Littérature. Após a Guerra, no retorno à cena literária francesa, a maior dificuldade para ele consistiu em se desfazer do rótulo de "regionalista" e abandonar o romance de costumes populares. As negociações para entrar para a Grasset (1921-1924) culminaram, enfim, com um contrato para publicação de no mínimo cinco livros.

Durante esse período, criou-se uma forte discussão sobre o "estilo" de Ramuz. Sintomática nos âmbitos francófonos, essa questão implicava uma outra essencial, a da nacionalidade e da relação com a língua francesa ${ }^{5}$ : "Quem quiser ser um escritor francês, que aprenda nossa língua!” - bradava um jornalista*. O primeiro manuscrito de Ramuz foi recusado por Bernard Grasset em 1921, em razão de sua linguagem “empolada”. Somente em 1924 Grasset e Ramuz acordaram o preço das reescritas subseqüentes. Era preciso estudar mais detidamente as reescritas consentidas em função de um novo editor e do público francês, a fim de premeditar os efeitos de campo que as suscitavam. Entretanto, a partir de 1924, cada um de seus romances passou a sair simultaneamente na Suíça, pela Mermod (Lausanne), e na França, pela Grasset. Em 1930, com o Prêmio Romand, foi sagrado autor nacional oficial, embora suas vendas permanecessem modestas na França, onde obteve, ainda assim, o reconheci-

${ }^{5}$ Sobre este assunto, ver meu ensaio sobre Rousseau, Töpffer e Ramuz: Le droit de "mal écrire". Quand les auteurs romands déjouent le "français de Paris". (Genebra: Zoé, 1998).
"(Bailly, Auguste citado por Ramuz, Charles-Ferdinand Pour ou contre C.-F. Ramuz. Cahier de témoignages. Paris: Editions du siècle, 1926.) 
mento de seus pares (Claudel, Céline, Barbusse, Cocteau). Assim, Claudel mencionou o "grande romancista" suíço, a exemplo de Henri Barbusse. Henry Poulaille, por sua vez, procurou classificar Ramuz como "um dos vinte grandes escritores de sua época”. Em termos de gênero, Ramuz realizou ao longo desses anos uma passagem importante: do romance pós-naturalista com paisagem regionalista (de 1905 a 1914) ao romance poético (a partir de 1918 aproximadamente). Essa reorientação lhe permitiu ser considerado, no campo restrito, como um "inventor de estilo" (por Céline, Barbusse, e, depois, R. Pinget).

Ao contrário de Cendrars, e por motivos biográficos, Ramuz dispunha de uma base editorial suíça e de um rótulo nacional estáveis que lhe permitiram publicar em conjunturas favoráveis e ser bastante beneficiado pelo protegido mercado helvécio. Mas prejudicaram-no também, reduzindo-o equivocadamente à imagem de um "regionalista", e até, em razão dos mal-entendidos culturais inerentes às traduções,

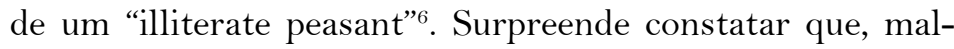
grado um alto nível de reconhecimento no campo restrito durante a sua vida, Ramuz, certamente por questões de nacionalidade, não tenha sido, como Cendrars, considerado pela historiografia literária francesa do século XX, já que encarna, quase até a caricatura, o autor helvécio por excelência. Foi à custa de novas leituras da evolução do gênero romanesco nos anos 1990 e dos reiterados esforços surgidos no meio universitário que se concluiu, em 1999, o projeto de reunir os romances de Ramuz na Bibliothèque de la Pléiade, forma francesa por excelência do panteão literário ${ }^{7}$.

\section{Trajetórias típicas?}

Esses dois exemplos não dão conta de todas as trajetórias possíveis, mas combinam de modos variados os parâmetros e, com base neles, podem ser observadas trajetórias típicas. Como exemplo, uma geração posterior, a de Maurice Chappaz (nascido em 1916) e Georges Borgeaud (1914-1998). O primeiro, poeta, escolheu publicar apenas na Suíça, onde obteve grande consagração, só se deixando conhecer tardia e mo-

\footnotetext{
6 "Camponês iletrado", contracapa da tradução inglesa de Aline.

${ }^{7}$ Os dois volumes de Romans sairão pela Gallimard em 2005.
} 
destamente no campo francês por intermédio de atentos promotores culturais (Bolsa Goncourt de Poesia, 1997; Evangile selon Judas. Paris: Gallimard, 2001). O segundo, romancista, estabeleceu-se em Paris, freqüentou os círculos da NRF, obtendo em seguida o Renaudout (1974) e o prêmio Médicis de ensaio (1986), sem interromper publicações e intervenções no subcampo helvécio (revistas, imprensa), em que reinvestiu o crédito simbólico obtido na França. Na geração seguinte, há Jacques Chessex (nascido em 1934), prêmio Goncourt de 1973. Estabelecido por escolha própria na Suíça, publicou tanto neste país quanto na França, representando um caso intermediário parecido com o do valdense Edouard Rod. Este foi um defensor precoce de Zola que fez carreira literária na Suíça e na França, tendo publicado, em ambos os países, gêneros adequados às suas tradições: romance na França, novelas e romances alpinos na Suíça. Levou, no fim de sua vida, o delicado cognome de "Anatole Suisse".

Todos esses casos permitem ver que o campo francês tende ora a abstrair a origem dos autores por ele consagrados ${ }^{8}$, ora a remetê-los, quando não os reconhece diretamente como seus, ao exotismo (assim, a imagem positiva de Nicolas Bouvier) ou ao provincianismo (sob a forma do estigma). Sem ceder à ilusão das origens, poderíamos constatar que essa alternativa já fora utilizada para com o "cidadão" de Genebra Jean-Jacques Rousseau, ora associado à sua condição de "indigente" suíço (Voltaire), ora (postumamente) designado e assimilado pelo campo literário francês como um dos pais fundadores da modernidade ${ }^{9}$.

Tradução: Matosalém Vilarino Pereira

\footnotetext{
${ }^{8} \mathrm{~A}$ ponto de os leitores ignorarem freqüentemente suas nacionalidades $(\mathrm{H}$. Michaux, Ph. Jaccottet).

${ }^{9}$ Sobre a trajetória franco-suíça de Rousseau, cf. nossos trabalhos "Recherches sur la posture: Rousseau” (Littérature, n. 126, Larousse, juin 2002: 3-17) e Le Gueux Philosophe (Jean-Jacques Rousseau), ensaio publicado em 2003.
} 
Jérôme Meizoz

Nascido em 1967. Doutor em Letras e sociólogo da cultura (EHESS, Paris), ensina literatura francesa na Universidade de Lausanne. É autor de inúmeros ensaios, entre os quais Ramuz. Un passager clandestin des lettres françaises (Zoé, 1997), Le Droit de "mal écrire" (Zoé, 1998), L'Âge du roman parlant 1919-1939 (Droz, 2001), Le Gueux philosophe (Jean-Jacques Rousseau)(Antipodes, 2003) e L'oeil sociologue et la littérature (Slatkine Erudition, 2004), e de textos de ficção, como Morts ou vif (Zoé 1999), Destinations païennes (Zoé, 2001) e Jours rouges (En Bas, 2003).

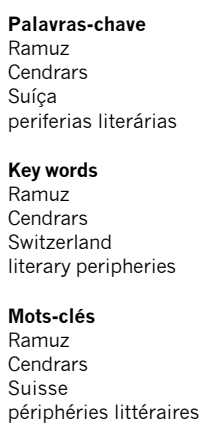

Recebido em 31/10/2003

Aprovado em
15/03/2004

\section{Resumo}

Comparação da trajetória de dois autores helvéticos, cujos relacionamentos com o campo literário francês se mostram radicalmente opostos, tanto em suas escolhas domiciliares, suas bases editoriais, quanto em sua imaginação literária. Enquanto Ramuz, ao fazer da necessidade uma virtude, apóia-se sobre a literalização da experiência do lugar, Cendrars estabelece uma literatura do desenraizamento e da errância. Cada um deles contornou a seu modo a desvantagem de pertencer a uma nação literária menor (no sentido de Kafka).

\section{Abstract}

Comparison of the biographies of two Helvetian writers, whose relationships with the French literary scene proved to be radically opposed, both in terms of their choices of residence, their editorial support and their literary imagination. While Ramuz, making a virtue out of necessity, relies on the literalization of the experience of place, Cendrars develops a literature of rootlessness and straying away. Each one of them had his own way to bypass the handicap of belonging to a minor literary nation (in the sense of Kafka).

\section{Résumé}

Comparaison de la trajectoire de deux auteurs de nationalité helvétique, dont les rapports au champ littéraire français apparaissent comme radicalement opposés, tant dans leurs choix domiciliaires, leurs supports éditoriaux que dans leur imaginaire littéraire. Alors que Ramuz, faisant de nécessité vertu, s'appuie sur la littérarisation de l'expérience du lieu, Cendrars impose une littérature du déracinement et de l'errance. Chacun a contourné à sa manière le handicap qui consiste à appartenir à une nation littéraire mineure (au sens de Kafka). 